\title{
Nanoemulsion as a carrier to improve the topical anti-inflammatory activity of stem bark extract of Rapanea ferruginea
}

This article was published in the following Dove Press journal:

International Journal of Nanomedicine

6 September 2016

Number of times this article has been viewed

\author{
Juarana Dal Mas' \\ Tailyn Zermiani' \\ Liliani C Thiesen' \\ Joana LM Silveira ${ }^{2}$ \\ Kathryn ABS da Silva' \\ Márcia M de Souza' \\ Angela Malheiros' \\ Tania MB Bresolin' \\ Ruth M Lucinda-Silva' \\ 'NIQFAR, Graduate Program in \\ Pharmaceutical Sciences, University \\ of Vale do Itajaí, Itajaí, Santa Catarina, \\ Brazil; '2Department of Biochemistry \\ and Molecular Biology, Federal \\ University of Paraná, Curitiba, \\ Paraná, Brazil
}

\begin{abstract}
The aim of this study was to develop nanoemulsion containing soft extract of stem bark of Rapanea ferruginea to improve the topical delivery and anti-inflammatory activity. The extract of $R$. ferruginea stem bark was incorporated into the oily phase of the nanoemulsion by the method of phase inversion at low energy. The developed nanoemulsion had an average droplet size of $47.88 \pm 8.20 \mathrm{~nm}$ and a polydispersibility index of 0.228 . Uniformity of size, spherical shape of droplet, and absence of clusters were confirmed by transmission electronic microscopy. The zeta potential was $-34.7 \pm 1.15 \mathrm{mV}$. The nanoemulsion showed a moderate degree of skin irritation in the agarose overlay assay in vitro. The content of the extract markers, myrsinoic acids $\mathrm{A}$ and $\mathrm{B}$, was $54.10 \pm 0.08$ and $53.03 \mu \mathrm{g} / \mathrm{g}$ in the formulation, respectively. The formulation demonstrated pseudoplastic and thixotropic rheological behavior. In vitro release of chemical markers was controlled by diffusion mechanism. An extract-loaded nanoemulsion showed a topical anti-inflammatory activity in a croton oil-induced edema ear model, with a decrease in tumor necrosis factor release and myeloperoxidase activity. The nanoemulsion was $160 \%$ more efficient than the conventional cream containing $0.13 \%$ of the extract. The nanoemulsion showed suitable properties as a carrier for topical use of $R$. ferruginea extract and the approach for improving the topical anti-inflammatory activity.
\end{abstract}

Keywords: nanotechnology, nanoemulsion, Rapanea ferruginea, anti-inflammatory, phytomedicine

\section{Introduction}

Cutaneous inflammatory diseases may arise due to modification in the skin's defense mechanisms, by inadequate immunologic activity, or by external agents of aggression, which cause structural and functional alterations in the skin. ${ }^{1-3}$ Cutaneous inflammation is a common disease that is induced and maintained by the interaction among many cells populations. ${ }^{3,4}$ The epidermal and dermal cells are known as the cytokines producers, with keratinocytes being the largest producer of cytokines and adhesion molecules. ${ }^{5,6}$ Of the cytokines produced by keratinocytes, only interleukin (IL)-1 $\alpha,-1 \beta$, and tumor necrosis factor (TNF) activate a sufficient number of effector mechanisms to trigger skin inflammation.?

The therapeutic use of herbal products has been successful in the treatment of skin disorders for thousands of years in Europe and Asia, and such products are still being used due to their effectiveness, with scientific validation of the use of some species. ${ }^{8}$ However, although phytomedicines show better therapeutic activity in vitro, they have the least in vivo efficacy due to many characteristics, such as poor solubility, inadequate molecular size, or both, resulting in failure of absorption and poor systemic availability. ${ }^{9,10}$
Correspondence: Ruth M Lucinda-Silva Graduate Program in Pharmaceutical Sciences, University of Vale do Itajaí, Rua Uruguai, 458, Itajaí, Santa Catarina, Brazil Tel +55 $47334 \mid 78$ I I

Fax +55 4733417744

Email rlucinda@univali.br 
The development of new emulsified carriers of topical drugs for the purpose of overcoming bioavailability and stability problems is very important for the production of medicines. ${ }^{10-12}$ Nanosystems, such as nanoemulsions, are dermatological carriers that improve drug release profile, occlusion and dermal drug permeation. ${ }^{12,13}$ A nanoemulsion is a transparent or translucent emulsified system with nanometer-sized droplets ${ }^{14-17}$ that improves the bioavailability of herbal products. ${ }^{11}$ There are many advantages of using nanoemulsions as a carrier for topical drug delivery, such as the incorporation of hydrophilic and lipophilic drugs, reduced toxic and irritant effects compared to microemulsions, high interfacial area, protection of the drugs from hydrolysis and oxidation, increased drug permeation through the skin, more pleasant sensorial characteristics, and relatively lower surfactant concentration. ${ }^{15-17}$ Considering the advantages of nanoemulsions, many studies on incorporation of herbal drugs into these systems have been carried. ${ }^{11,18-21}$

Rapanea ferruginea (Ruiz \& Pav) Mez (synonymy Myrsine coriacea) is a tree popularly known in Brazil as capororoca. Its leaves and stem barks are prepared as tea and are recommended, in popular use, to treat diseases of the urinary tract, as well as itching, rashes, hives, eczema, rheumatism, and diseases of the liver. ${ }^{22}$ In previous studies by our research group, $R$. ferruginea and markers myrsinoic acids A and B (MAA and MAB) showed antiinflammatory and analgesic effects when administered through oral and intravenous routes. ${ }^{22-24}$ Although other studies have shown that myrsinoic acids isolated from Myrsine species have anti-inflammatory activities, ${ }^{25,26}$ there are no reports about the topical anti-inflammatory activity of $R$. ferruginea extracts.

In this study, the soft extract (SE) of the stem bark of $R$. ferruginea was incorporated into a nanoemulsion, and physical-chemical characteristics and release profile were determined. Moreover, in vivo anti-inflammatory topical activity, the cellular mechanism, and histological analysis were studied. The nanoemulsion system was compared with a conventional semisolid formulation to investigate the carrier's influence in the improvement of the topical activity of the extract.

\section{Materials and methods Materials}

PEG-40 hydrogenated castor oil (PHCO; Alkest ${ }^{\circledR}$ CSO 400) was supplied by Oxiteno (São Paulo, Brazil). Phenoxyethanol, methylparaben, ethylparaben, propylparaben, butylparaben, and isobutylparaben (Phenonip ${ }^{\circledR}$ ) were purchased from
Clariant (Muttenz, Switzerland). Isopropyl miristate, propylene glycol, and sorbitan oleate were purchased from Pharma Special (Itapevi, São Paulo, Brazil), Casa das Essências (São Paulo, Brazil), Via Farma, Ltd. (São Paulo, Brazil), Sigma-Aldrich Co. (St Louis, MO, USA), and Fagron (São Paulo, Brazil), respectively. Methanol (J T Barker, Center Valley, PA, USA), acetonitrile (Tedia Brasil, Rio de Janeiro, Brazil), and phosphoric acid (Merck, Darmstadt, Germany) of high performance liquid chromatography (HPLC) grade were used. Croton oil was purchased from Sigma-Aldrich Co. The chemical markers MAA and MAB with HPLC purity of $76.2 \%$ and $98.9 \%$, respectively, were isolated by our research group. ${ }^{27,28}$

Stem barks of authentic $R$. ferruginea were collected in Blumenau (Santa Catarina, Brazil) (latitude: 2697'69.66"S, longitude: 49/06'24.31"W, and altitude: $200 \mathrm{~m}$ ) in October 2013 and identified by Prof Renê Artur Ferreira. A voucher specimen was deposited at the Barbosa Rodrigues Herbarium (Itajaí-SC, Brazil) under the number HBR 52715. The $R$. ferruginea SE containing $51.17 \% \pm 0.53 \%(\mathrm{w} / \mathrm{w})$ of total solid, $40.06 \pm 0.02 \mathrm{mg} / \mathrm{g}$ of MAA, and $37.34 \pm 0.09 \mathrm{mg} / \mathrm{g}$ of MAB was prepared using the method standardized by Baccarin et $\mathrm{al}^{29,30}$ and analyzed by validated HPLC method, according to Zermiani et al. ${ }^{31}$

\section{Preparation of the nanoemulsion containing the $R$. ferruginea SE}

A nanoemulsion was developed from a pseudoternary phase diagram using PHCO and sorbitan oleate as surfactants and isopropyl myristate as oil (data not published). The oil phase, containing $0.13 \% R$. ferruginea dissolved in propylene glycol (2\%), isopropyl myristate $(20.0 \%), \mathrm{PHCO}+$ sorbitan oleate (7.2:1.5) $(13.3 \%)$, and the preservative $0.75 \%$ (Phenonip ${ }^{\circledR}$ ), was heated to $80^{\circ} \mathrm{C}$. The aqueous phase $\left(65.95 \%\right.$ water, $\left.80^{\circ} \mathrm{C}\right)$ dropped while stirring at $600 \mathrm{rpm}$ and $80^{\circ} \mathrm{C}$. After 5 minutes, the heating was stopped and the formulation stirred for 3 minutes. After cooling, Sepige ${ }^{\circledR}(0.85 \%)$ was added and the nanoemulsion was placed in an aluminum-coated tube.

\section{Characterization of nanoemulsion}

\section{Visual aspects and physical stability}

The nanoemulsions were analyzed for visual aspects such as color, phase separation and creaming, and physical stability after centrifugation for 30 minutes at $2,500 \times \mathrm{g}$.

\section{Particle size analysis}

The sizes of the nanoemulsion droplets were measured at $25^{\circ} \mathrm{C}$ by photon correlation spectroscopy (Zetasizer NanoZS 
ZEN 3600, Malvern Instruments, Malvern, UK). All samples were previously diluted with ultrapure water in a ratio of 1:100. Measurements were performed at a fixed angle of $173^{\circ}$ using a $633 \mathrm{~nm}$ laser, with each data point being the average of three independent measurements. Average diameter and polydispersity index (PDI) were calculated from analysis of the autocorrelation function.

\section{Zeta potential analysis}

Zeta potential was measured using the Zetasizer NanoZS ZEN 3600 (Malvern Instruments). All samples were previously diluted with ultrapure water in a ratio of $1: 100$ and analyzed in triplicate.

\section{Morphological evaluation}

Morphological aspects of the nanoemulsions were analyzed by transmission electronic microscopy using a JEM-1,200 EXII instrument (JEOL, Tokyo, Japan). All samples were diluted with distillated water in a ratio of 1:100. A drop of the solution was placed on a carbon-coated copper grid (400 mesh) overlayed with formvar/carbon and stained by $2.0 \%$ uranyl acetate aqueous solution for 10 minutes and examined by transmission electronic microscopy at $80 \mathrm{kV}$ at room temperature.

\section{Rheological behavior analysis}

Rheological behavior was analyzed in triplicate, at $25^{\circ} \mathrm{C}$, using a cone-and-plate type rotational viscometer (Haake VT 550, Thermo Fisher Scientific, Waltham, MA, USA). The analysis was conducted in three steps: in the first step, the shear rate was increased from 0.0 to $80.0 \mathrm{~s}^{-1}$ for 180 seconds for collecting 100 linear data; in the second step, the shear rate was kept constant at $80.0 \mathrm{~s}^{-1}$ for 180 seconds for collecting 100 data; and in the last step, the shear rate was decreased from 80.0 to $0.0 \mathrm{~s}^{-1}$ seconds for 180 seconds for collecting 100 more data. Power law index and thixotropic behavior were determined using the software Rheowin ${ }^{\circledR} 4$ Data Manager (Thermo Fischer Scientific, Waltham, MA, USA).

\section{Evaluation of mirsinoic acids content in the nanoemulsions}

MAA and MAB contents were determined using the HPLC gradient method developed and validated by Zermiani et al. ${ }^{31}$ The chromatographic system was a Shimadzu LC 20-AC (Kyoto, Japan), equipped with a Shimadzu LC-20 AT quaternary pump, a Shimadzu SPD-M20A photodiode array detector, a Shimadzu SIL-20AHT auto-sampler, and a software LC Solution. Reversed-phase column
$(150 \times 4.6 \mathrm{~mm})$ of $2.6 \mu \mathrm{m}$ core-shell particles (Kinetex ${ }^{\circledR} \mathrm{XB}$ C18) (Phenomenex, Torrance, CA, USA) was used as a stationary phase. The mobile phase consisted of a mixture of methanol:acetonitrile:acidified water (phosphoric acid, $\mathrm{pH}$ 2.5 ), with a flow rate of $0.9 \mathrm{~mL} / \mathrm{min}$, an injection volume of $20 \mu \mathrm{L}$, and a temperature of $35^{\circ} \mathrm{C}$. The gradient elution was programmed as follows: $0-2 \mathrm{~min}$ (25:5:70), 2-5 $\mathrm{min}$ (25:30:45), 5-10 $\min (25: 60: 15), 10-12 \min (20: 70: 10)$, 12-15 $\mathrm{min}$ (15:75:10), 15-20 $\mathrm{min}(15: 84: 1)$ and 20-30 $\mathrm{min}$ (25:5:70). The optical absorbance was monitored at $260 \mathrm{~nm}$ for MAA and at $270 \mathrm{~nm}$ for MAB.

Therefore, aliquots of $0.5 \mathrm{~g}$ of the nanoemulsions were diluted with $5 \mathrm{~mL}$ of acetonitrile and submitted to an extraction process for 20 minutes of ultrasound bath. The solutions obtained were centrifuged at 2,500× $g$ for 10 minutes, and the supernatants were filtered and analyzed in triplicate.

\section{In vitro skin irritation test of the nanoemulsions}

The cutaneous irritation of the nanoemulsions and SE was evaluated by the agarose overlay assay according to the United States Pharmacopeia ${ }^{32}$ and O'Brien et al. ${ }^{33}$ The size of the lysis area was determined and irritation degree classification was performed according to the United States Pharmacopeia. ${ }^{32}$

\section{In vitro release studies of the nanoemulsion}

The release profile of the markers MAA and MAB of $R$. ferruginea extract incorporated in the nanoemulsion, in the cream and in the propylene glycol solution $(0.13 \% \mathrm{SE})$ was determined using Franz type diffusion cells (Hanson Research, Chatsworth, CA, USA) $(n=6)$. For the release studies, dialysis membranes were used (Sigma-Aldrich Co.).

A 70\% hydroalcoholic solution was used as the receptor medium to ensure sink conditions. The donor compartment was filled with the formulations being tested. Subsequently, $1 \mathrm{~mL}$ samples were collected from the receptor compartment at $1,2,4,6,8,12$, and 24 hours after starting the analysis and replaced with the same volume of receptor medium. All samples were filtered and analyzed by HPLC using the methods described in the "Evaluation of mirsinoic acids content in the nanoemulsions" section. The cumulative amount of MAA and MAB released through the membrane per area of diffusion was plotted as a function of time.

The release profiles obtained from formulations were fitted to zero order, first order, Higuchi model, and general release equation. 


\section{Pharmacological study}

\section{Animals}

All procedures used in the present study followed the "Principles of Laboratory Animal Care" in the National Institutes of Health publication No 85-23 and were approved by the Animal Ethics Committee of Universidade do Vale do Itajaí (protocol numbers 03/2014).

Female Swiss mice (25-30 g) obtained from the Universidade do Vale do Itajaí (UNIVALI, Itajaí, Brazil) were used in this study. The animals were housed under conditions of optimum light, temperature, and humidity ( 12 hours light-dark cycle, $22^{\circ} \mathrm{C} \pm 2^{\circ} \mathrm{C}$ ), with food and water provided ad libitum.

\section{Evaluation of the in vivo anti-inflammatory activity of the $R$. ferruginea extract incorporated into the nanoemulsion}

The nanoemulsion and cream containing the $R$. ferruginea SE were evaluated for the anti-inflammatory activity according to the croton oil-induced edema ear model described by Carlson et al, ${ }^{34}$ with some modifications.

The formulations were applied topically to the inside of the right ear of the mice 30 minutes before the application of $20 \mu \mathrm{L}$ of croton oil $(2.5 \% \mathrm{r} / \mathrm{v}]$ diluted in acetone) on the outside of the right ear. The thickness of the ears (right and left) was measured 6 hours after induction of inflammation using a micrometer (Mitutoyo Series 293). Edema was expressed as the increase in ear thickness due to the inflammatory process. To measure the thickness of the ears, the micrometer was applied near the tip of the ear, slightly distal to the cartilaginous ridges, and the thickness was recorded in $\mu \mathrm{m}$.

\section{Effects of treatment with nanoemulsion containing the $R$. ferruginea extract on IL-I $\beta, T N F$, and KC production}

IL-1 $\beta$, TNF, and keratinocyte-derived chemokine (KC) levels were measured as described by Otuki et al. ${ }^{35}$ Animals were pretreated with different concentrations of formulations 30 minutes before the induction of inflammation, and the cytokine levels were determined 6 hours after the application of croton oil. The assay used was an enzyme-linked immunosorbent assay (ELISA). The ear tissue samples ( $6 \mathrm{~mm}$ punch) were collected and homogenized in phosphate-buffered saline containing $0.05 \%$ Tween $20,0.1 \mathrm{mM}$ phenylmethylsulfonyl fluoride, $0.1 \mathrm{mM}$ benzamethonium chloride, $10 \mathrm{mM}$ ethylenediaminetetraacetic acid, and $20 \mathrm{UI}$ aprotinin A and then centrifuged at $3,000 \times g$ for 10 minutes before being stored at $-80^{\circ} \mathrm{C}$ until further analysis. IL- $1 \beta, \mathrm{TNF}$, and $\mathrm{KC}$ levels were measured using an ELISA kit (R\&D Systems, Minneapolis, MN, USA) according to the manufacturer's instructions. Results were expressed as pg of the cytokine/ $\mathrm{mg}$ of the tissue.

Tissue MPO activity in the inflamed skin treated with nanoemulsion containing the $R$. ferruginea extract

Neutrophil recruitment into the mice ears was estimated indirectly by measuring the activity of myeloperoxidase (MPO) in the ear tissue. The activity of the enzyme was assayed as described previously. ${ }^{36}$ The animals were treated with the nanoemulsion containing the $R$. ferruginea extract 30 minutes before the application of croton oil. The ear tissue samples ( $6 \mathrm{~mm}$ punch) were collected 6 hours after the application of croton oil, homogenized at $5 \%(\mathrm{w} / \mathrm{v})$ in ethylenediaminetetraacetic acid/ $\mathrm{NaCl}$ buffer $(\mathrm{pH} 4.7)$ and centrifuged at $10,000 \times g$ for 15 minutes at $4^{\circ} \mathrm{C}$. The pellet was resuspended in $0.5 \%$ hexadecyltrimethyl ammonium bromide buffer ( $\mathrm{pH}$ 5.4), and the samples were frozen and thawed three times in liquid nitrogen. The samples were centrifuged $\left(10,000 \times g, 15\right.$ minutes at $\left.4^{\circ} \mathrm{C}\right)$ and $25 \mu \mathrm{L}$ of the supernatant was used for the MPO assay. The enzymatic reaction was assessed with $1.6 \mathrm{mM}$ tetramethylbenzidine, $80 \mathrm{mM}$ sodium phosphate buffer $\mathrm{pH} 7.2$, and $0.3 \mathrm{mM}$ hydrogen peroxide. The optical absorbance was measured at $650 \mathrm{~nm}$. The results were expressed as the optical density per milligram of tissue.

\section{Histological analysis in inflamed skin treated with cream and nanoemulsions containing the $R$. ferruginea} extract

At the end of the anti-inflammatory analysis, $6 \mathrm{~mm}^{2}$ fragments were collected from the right ear of all the animals and fixed in $4 \%$ paraformaldehyde. These were embedded in paraffin wax and subsequently sectioned at $4 \mu \mathrm{m}$ intervals and stained with hematoxylin and eosin. A representative area of ear sample was selected for qualitative microscopic analysis of the cellular infiltrate and edema (dermal thickness). A naive group was included for comparison with the other experimental groups.

\section{Statistical analysis}

The results are presented as the mean \pm standard error of the mean of six animals. Statistical comparisons of the data were performed by analysis of variance and the Newman-Keuls multiple comparison test using GraphPad Prism 5 (GraphPad Software, Inc., La Jolla, CA, USA) software. The level of significance was considered as $P<0.05$. 
Table I Results of the nanoemulsion with and without soft extract of Rapanea ferruginea characterization

\begin{tabular}{|c|c|c|c|c|c|c|c|c|}
\hline Samples & Droplet size (nm) & PDI & $\zeta$-potential $(\mathrm{mV})$ & Viscosity (mPa.s) & Thixotropy $\left(\mathrm{Pa}^{-1}\right)$ & $\mathbf{n}^{\mathbf{a}}$ & MAA $(\mu g / g)$ & MAB $(\mu g / g)$ \\
\hline NE & $57.43 \pm 3.37$ & $0.114 \pm 0.016$ & $-19.95 \pm 0.21$ & $7,356.34 \pm 303.59$ & $2.99 \times 10^{7}$ & 0.023 & - & - \\
\hline NESE & $47.88 \pm 8.20$ & $0.228 \pm 0.004$ & $-34.7 \pm 1.15$ & $5,773.28 \pm 950.85$ & $1.90 \times 10^{7}$ & 0.006 & $54.10 \pm 0.08$ & $53.03 \pm 0.03$ \\
\hline
\end{tabular}

Notes: aFlow index determined by analyzing flow behavior using the Ostwald-the-Waele model. "-” means without MAA and MAB.

Abbreviations: MAA, myrsinoic acid A; MAB, myrsinoic acid B; NE, nanoemulsion; NESE, nanoemulsion containing soft extract; PDI, polydispersity index.

\section{Results}

\section{Characterization of the nanoemulsions}

The nanoemulsion without SE (NE) showed semisolid consistency, homogeneity, white color, and mild texture, while nanoemulsion containing SE (NESE) showed a caramel color, semisolid consistency less than NE, homogeneity, mild texture, and reddish color characteristic of SE.

The physical-chemical properties found in the NE and NESE are summarized in Table 1. NE showed an average particle size of $57.43 \mathrm{~nm}$. The SE-loaded nanoemulsion showed an average particle size of $47.88 \mathrm{~nm}$. The PDI was 0.114 and 0.228 for NE and NESE, respectively. The size distribution and correlation rate are shown in Figure 1.
The nanoemulsions showed a narrow size distribution and only one size population.

The morphology of the nanoemulsion droplets showed a spherical form without aggregates (Figure 2). The SE-loaded nanoemulsion and the inert nanoemulsion showed a zeta potential value of $-34.7 \pm 1.15$ and $-19.95 \pm 0.21 \mathrm{mV}$, respectively (Table 1). The rheological behavior of the nanoemulsions was pseudoplastic with a flow index $<1.0$, calculated by power law and thixotropic behavior (Table 1 and Figure 3). The incorporation of SE in the system decreased the apparent viscosity and thixotropy.

The markers were successfully quantified by the validated chromatography method. ${ }^{31}$ The content of the extract
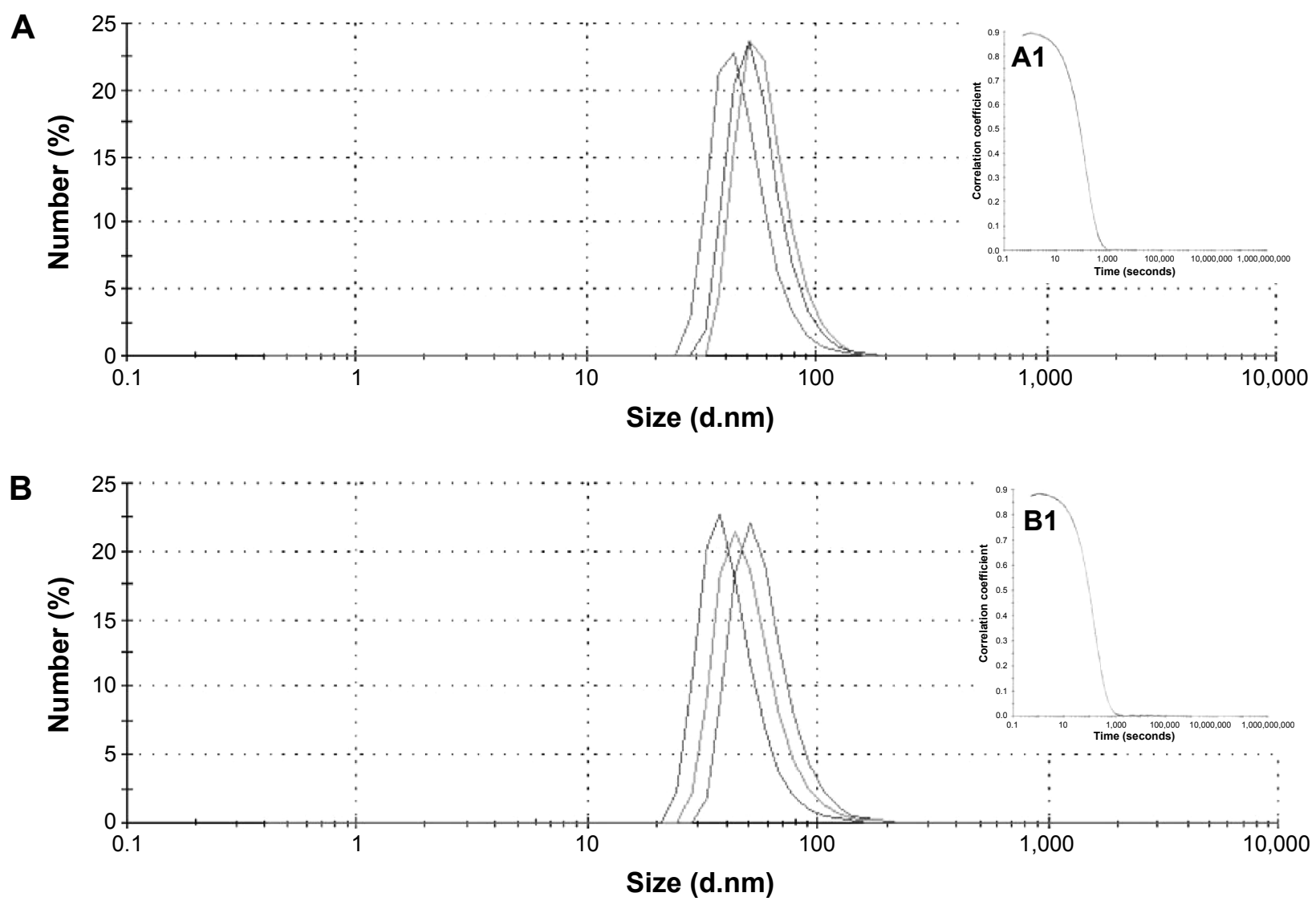

Figure I Profile of droplet size distribution of the nanoemulsions.

Notes: Representative graphs of the droplet size distribution of the nanoemulsion without $(\mathbf{A})$ and with the extract (B) of Rapanea ferruginea stem bark, and respective correlation rate graphs (AI and $\mathbf{B} \mathbf{I}$ inserts). 

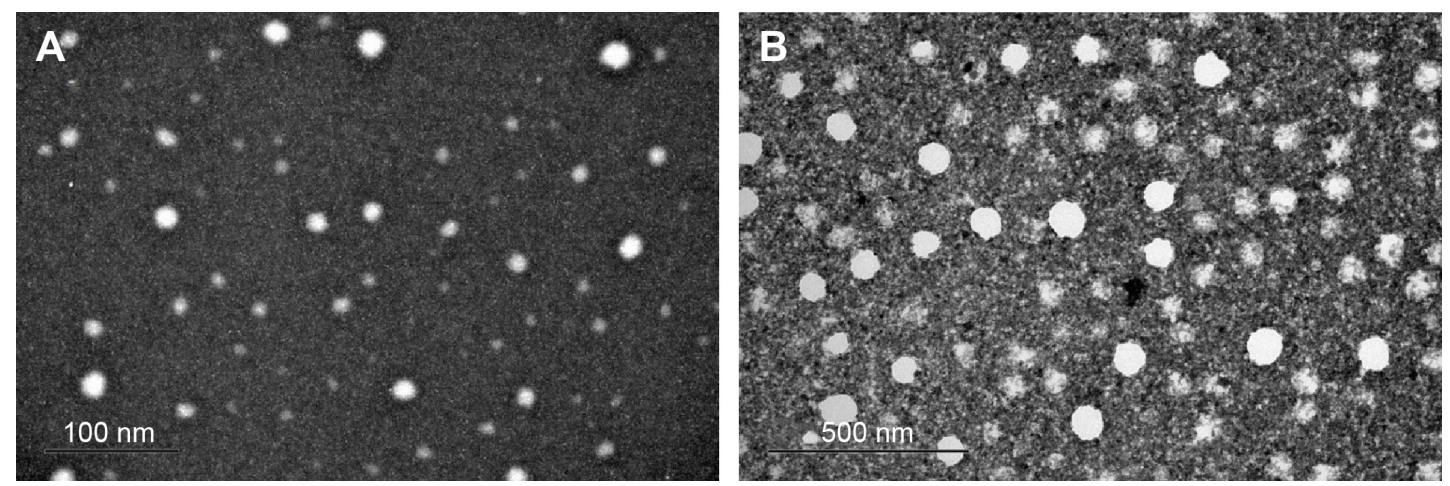

Figure 2 TEM images of the nanoemulsions.

Notes: Electronic micrographics obtained after negative contrast of the nanoemulsion without (A) and with the extract (B) of Rapanea ferruginea stem bark. $\times$ I5,000.
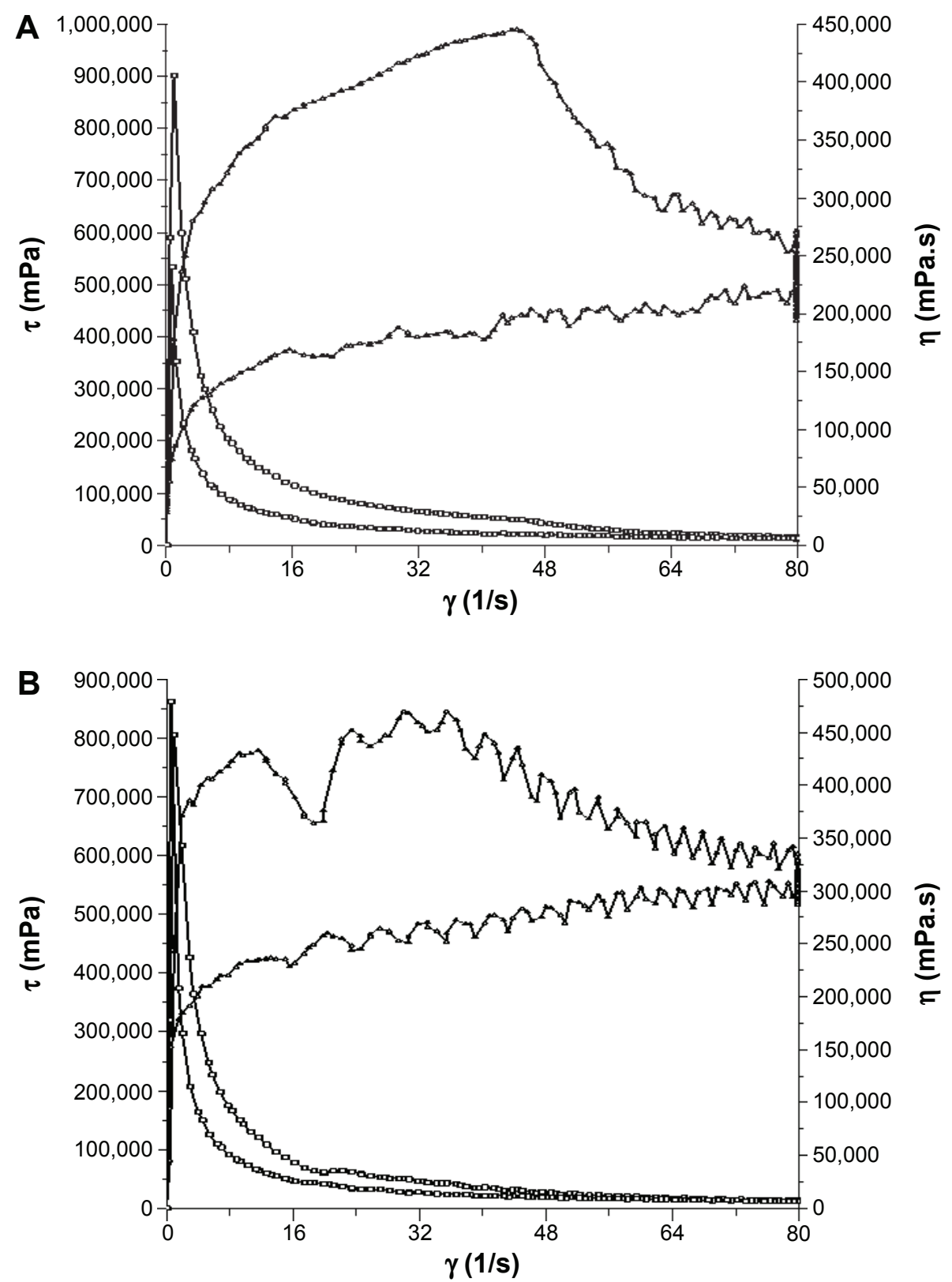

Figure 3 Viscosity and flow curve for the nanoemulsions.

Notes: Rheological behavior of the nanoemulsion without (A) and with the extract (B) of Rapanea ferruginea stem bark. 


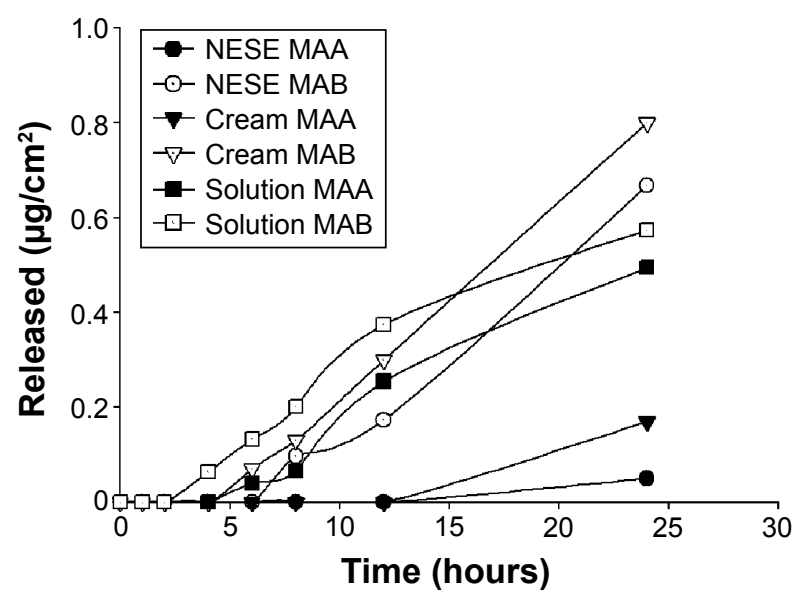

Figure $4 \mathrm{ln}$ vitro release profile of the markers MAA and MAB from propylene glycol solution, nanoemulsion and cream containing $0.13 \%$ of soft extract of Rapanea ferruginea stem bark, using Franz type diffusion cells ( $n=6$ cells).

Abbreviations: MAA, myrsinoic acid A; MAB, myrsinoic acid B; NESE, nanoemulsion containing soft extract.

markers MAA and MAB was $54.10 \pm 0.08$ (103.87\%) and $53.03 \pm 0.03 \mu \mathrm{g} / \mathrm{g}(109.25 \%)$ in the formulation, respectively.

\section{In vitro skin irritation test of the nanoemulsions}

The in vitro irritation potential of the nanoemulsions was at a moderate level and determined using the agarose overlay method according to the United States Pharmacopeia, ${ }^{31}$ with a lysis area average of $6.5 \pm 0.70$ and $7.25 \pm 0.35 \mathrm{~mm}$ for NESE and NE, respectively. The same assay realized with cream and SE showed no lysis area, which was indicated by the absence of irritation potential.

\section{In vitro release studies of the nanoemulsions}

In the release profile of the $R$. ferruginea $\mathrm{SE}$ incorporated into the nanoemulsion, both markers showed delayed release, with the MAB released after 6 hours, whereas MAA was detected after 12 hours of analysis (Figure 4). The release profile of the extract dissolved in propylene glycol also showed a lag time, but was of 2 and 4 hours to MAB and MAA, respectively. A similar release profile was observed in the extract from conventional semisolid formulation (cream) and from nanoemulsion; however, the MAB marker showed a faster release from the conventional formulation. The release profile from creams also displayed a lag time for both markers.

The release profiles of the markers were analyzed for release kinetic models. The release profile of MAB from all formulations and that of MAA from the extract solution showed a good fit to the models used $\left(R^{2}>0.97\right)$, with the exception of Higuchi's model $\left(R^{2}>0.73\right)$ (Table 2). The release profiles of the markers from the nanoemulsion and cream showed a good fit to the general release equation $\left(R_{2}>0.99\right)$ and release exponent $n$ was greater than 1.0. The kinetic results showed that the release not occurs for a specific mechanisms.

\section{Pharmacological study}

Figure 5 shows the effect of the cream and NESE under inhibition of croton oil-induced ear edema. The addition of the SE in the cream and the nanoemulsion caused edema to decrease in all treated ears. The nanoemulsion showed an improvement of $160 \%$ in the anti-inflammatory activity when compared to the edema inhibition activity of the conventional emulsion with the same amount of SE $(0.13 \%)$, which shows a statistically significant difference. The SE $0.13 \%$ nanoemulsion showed $90.50 \%$ edema inhibition, whereas SE $0.25 \%$ nanoemulsion inhibited $64.98 \%$ of edema. Conventional emulsions (cream) containing SE $0.13 \%, 0.25 \%$, and $0.5 \%$ showed anti-inflammatory activity with $56.53 \%, 58.64 \%$, and $64.65 \%$ edema inhibition, respectively. Compared to the control, the results were statistically significant, but there was no statistically significant difference between the concentrations studied.

The results of the assay of cytokines IL- $1 \beta$ and TNF (Figure 6) levels showed differences between the anti-inflammatory activities of the cream and nanoemulsion containing SE. The nanoemulsion decreased the levels

Table 2 Results of kinetic release analysis of MAA and MAB present in the Rapanea ferruginea soft extract (propylene glycol solution) and incorporated in the nanoemulsion and conventional semisolid (cream)

\begin{tabular}{|c|c|c|c|c|c|c|c|c|c|c|}
\hline \multirow[t]{3}{*}{ Formulation } & \multirow[t]{3}{*}{ Markers } & \multicolumn{9}{|c|}{ Kinetic models } \\
\hline & & \multicolumn{2}{|c|}{ Zero order } & \multicolumn{2}{|c|}{ First order } & \multicolumn{2}{|c|}{ Higuchi } & \multicolumn{3}{|c|}{ General release equation } \\
\hline & & $R^{2}$ & $K$ & $R^{2}$ & $K$ & $R^{2}$ & $K$ & $R^{2}$ & $K$ & $\mathbf{n}$ \\
\hline \multirow[t]{2}{*}{ Propylene glycol solution } & $M A B$ & 0.9795 & 0.0264 & 0.9772 & 0.0002 & 0.8552 & 0.0916 & 0.9771 & 0.0250 & 0.9993 \\
\hline & MAA & 0.9875 & 0.0255 & 0.9363 & 0.0002 & 0.7391 & 0.0665 & 0.9745 & 0.0049 & 1.4582 \\
\hline \multirow[t]{2}{*}{ Cream } & $M A B$ & 0.9992 & 0.0404 & 0.9400 & 0.0003 & 0.7319 & 0.1018 & 0.9955 & 0.0048 & 1.6124 \\
\hline & MAA & 1.0000 & 0.0141 & 0.7745 & $5.67 \times 10^{-5}$ & $0.564 I$ & 0.0189 & 0.9951 & $1.72 \times 10^{-7}$ & 4.342 \\
\hline \multirow[t]{2}{*}{ Nanoemulsion } & $M A B$ & 0.9948 & 0.0367 & 0.8992 & 0.0002 & 0.6830 & 0.0830 & 0.9957 & 0.0012 & 1.995 \\
\hline & MAA & 1.0000 & 0.0042 & 0.7746 & $1.67 \times 10^{-5}$ & 0.5774 & 0.0068 & 0.9951 & $5.06 \times 10^{-8}$ & 4.342 \\
\hline
\end{tabular}

Abbreviations: MAA, myrsinoic acid $A ; M A B$, myrsinoic acid $B$. 


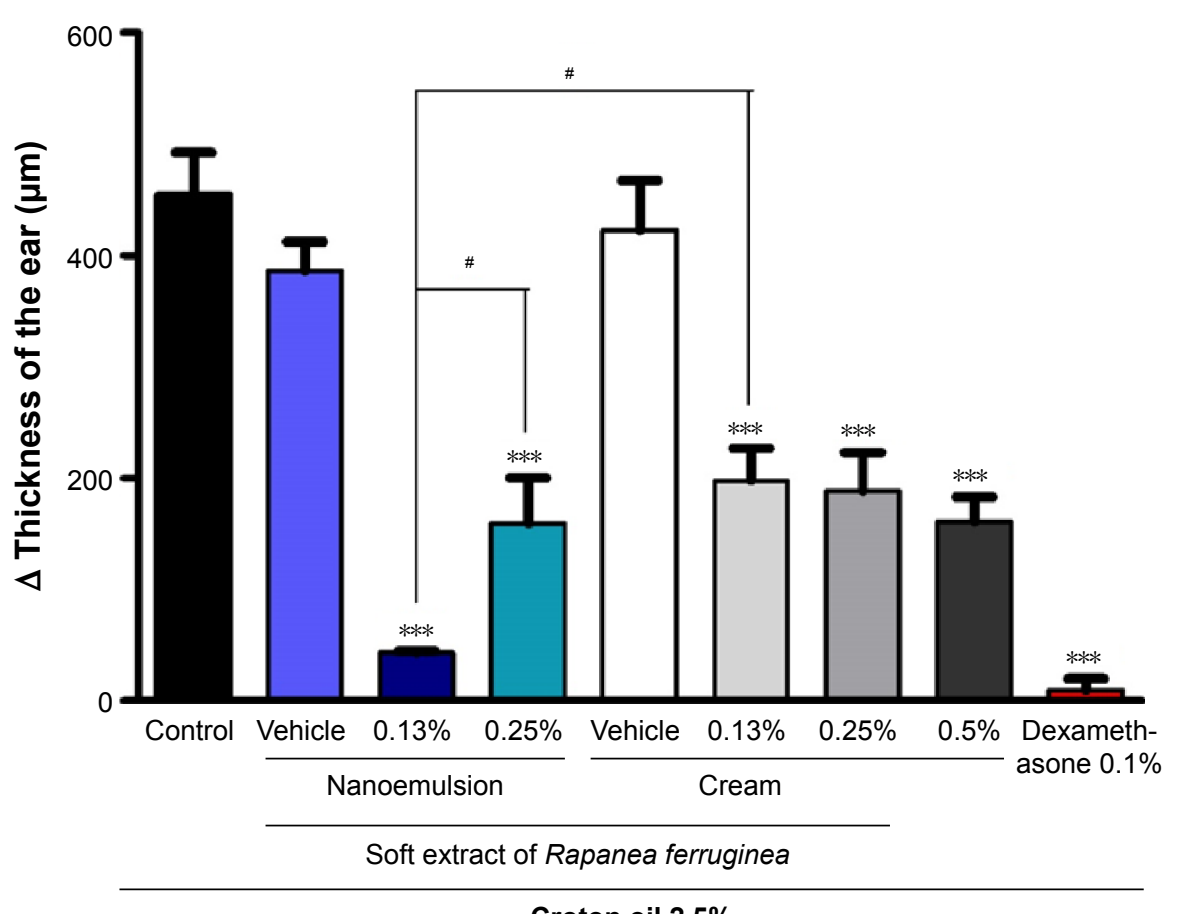

Croton oil $2.5 \%$

Figure 5 Effect of the nanoemulsions and creams containing soft extract of Rapanea ferruginea and dexamethasone topically administered on croton oil-induced ear edema. Notes: Edema was measured after 6 hours of the croton oil induction. Each bar represents the mean \pm standard error of the mean for six animals. The graphic symbol $(*)$ indicates the significance levels when compared with control group and (\#) indicates the significance level when compared between the groups. Significant difference of the controls, ${ }^{* * *} P<0.000 \mathrm{I}$ and difference between groups, ${ }^{*} P<0.05$.

of TNF better than cream, with a statistically significant difference. The levels of IL- $1 \beta$ did not a show significant difference between the carriers. The nanoemulsion decreased the amount of IL- $1 \beta$ and TNF to $40.96 \%$ (average amount $=668.49 \pm 39.4 \mathrm{pg} / \mathrm{mg}$ ) and $42.23 \%$ (average amount $=251.24 \pm 10.64 \mathrm{pg} / \mathrm{mg}$ ), respectively. The cream decreased the amount of IL-1 $\beta$ and TNF to $45.89 \%$ (average amount $=612.72 \pm 21.52 \mathrm{pg} / \mathrm{mg}$ ) and $28.72 \%$ (average amount $=309.95 \pm 2.47 \mathrm{pg} / \mathrm{mg}$ ), respectively.

The treatment with the nanoemulsion containing SE demonstrated more activity against MPO than the treatment with cream (Figure 6). The group treated with the nanoemulsion showed a significant decrease in enzymatic activity, corresponding to $64.60 \%$ of the inhibition (average amount $=0.355 \pm 0.06 \mathrm{DO} / \mathrm{mg}$ ) compared to the group treated with cream, which inhibited $31.30 \%$ of the enzymatic activity (average amount $=0.689 \pm 0.02 \mathrm{DO} / \mathrm{mg}$ ).

No statistically significant difference was observed between the groups treated with the nanoemulsion and cream containing SE against $\mathrm{KC}$ release (Figure 6). The group treated with the nanoemulsion decreased $\mathrm{KC}$ to $42.72 \%$ (average amount $=365.96 \pm 35.6 \mathrm{pg} / \mathrm{mg}$ ), whereas the group treated with cream showed a $57.90 \%$ decrease (average amount $=268.97 \pm 72.73 \mathrm{pg} / \mathrm{mg}$ ).
Histological analysis of the tissue in the control group treated only with $2.5 \%$ croton oil showed a thickened dermis with a high concentration of cellular infiltration and increased plasma extravasation compared to the naive group (Figure 7A and B).

The groups treated with cream and the nanoemulsion containing $0.13 \% R$. ferruginea extract (Figure $7 \mathrm{C}$ and D) presented reduced plasma extravasation and dermal thickness compared to the control group and showed topical anti-inflammation activities. They also exhibited a similar concentration of cells as the groups receiving cream and NE (Figure 7E and F), as well as the absence of dermal thickness and plasma extravasation reduction compared to the control group.

\section{Discussion}

The therapeutic use of herbal products has been successful in the treatment of skin disorders such as inflammatory and infectious processes. Hydroethanolic extracts from $R$. ferruginea stem barks showed anti-inflammatory and analgesic activities, but the markers myrsinoic acid A and B and others nonpolares substances present in the extract are poorly soluble in water. ${ }^{9,10}$

In the present study, the solubility of extract was verified in isopropyl myristate and caprylic/capric triglyceride 


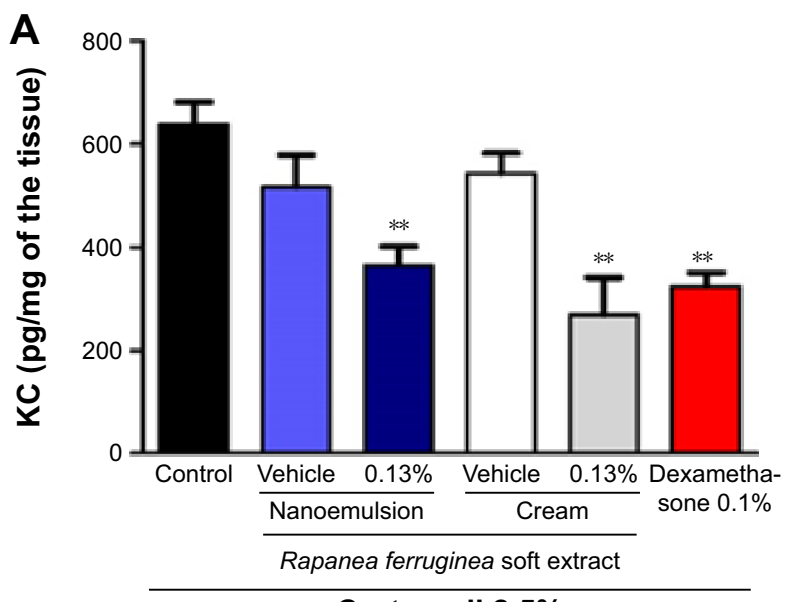

Croton oil $2.5 \%$

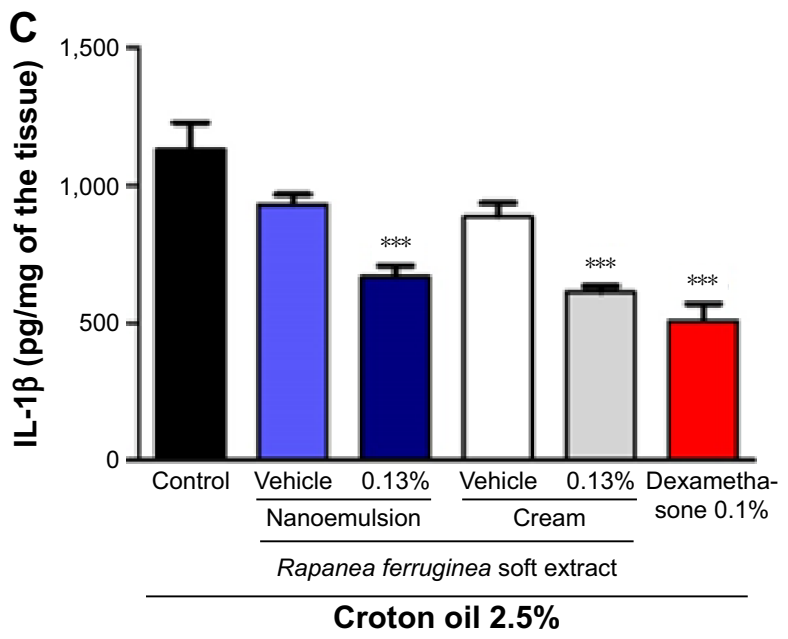

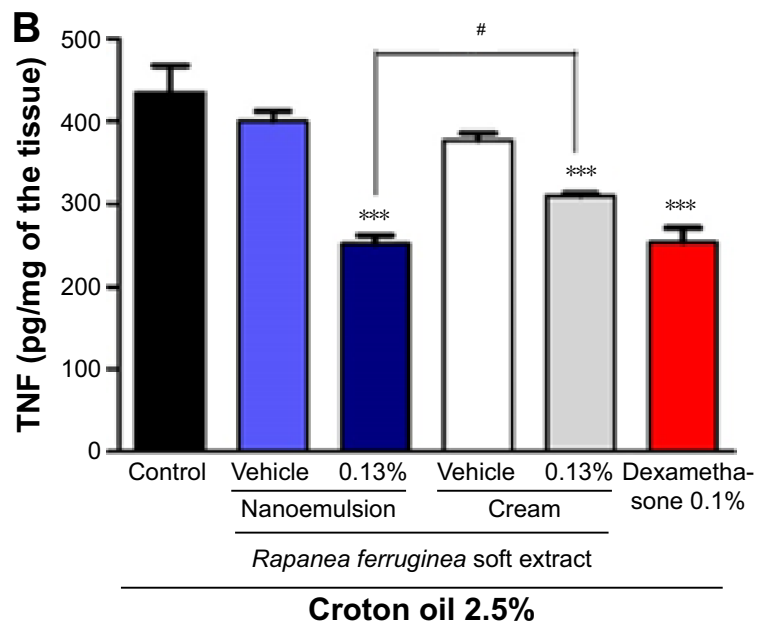

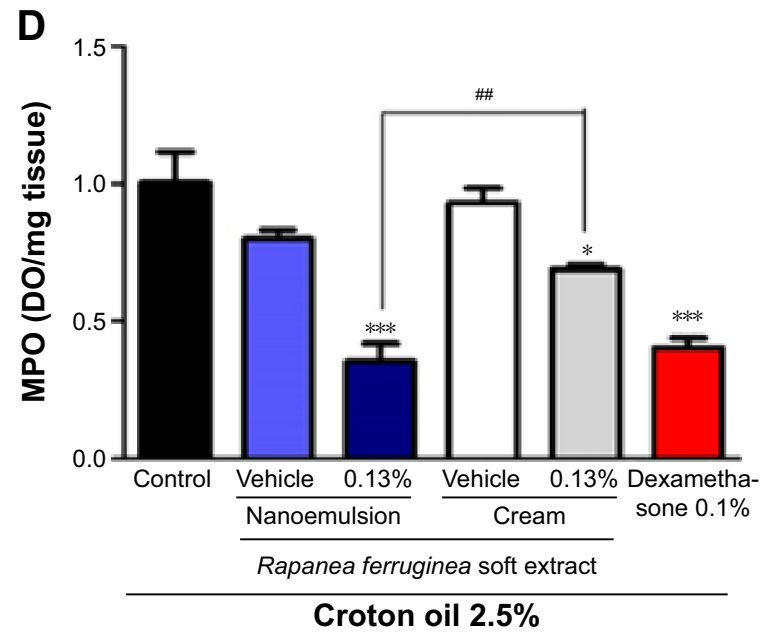

Figure 6 Anti-infammatory in vivo activity of the cream and nanoemulsion containing extract of Rapanea ferruginea stem bark.

Notes: Effect of the nanoemulsion and cream containing the Rapanea ferruginea extract on the inhibition of KC (A), on the production of TNF (B), IL-IB (C), and on MPO activity (D) in supernatants of homogenates from croton oil-treated ears. Each measure was realized after 6 hours of croton oil induction. Each bar represents the mean \pm standard error of the mean for six animals. The graphic symbol (*) indicates the significance levels when compared with control group and (\#) indicates the significance level when compared between the groups. Significant difference of the controls, ${ }^{*} * * P<0.000$ I, ${ }^{* *} P<0.01, * P<0.05$, and difference between groups, ${ }^{\#} P<0.0$ I, ${ }^{\#} P<0.05$. Abbreviations: IL, interleukin; KC, keratinocyte-derived cytokine; MPO, myeloperoxidase; TNF, tumor necrosis factor.

to select the emulsion oil phase. Isopropyl myristate was found to be a better solvent. PHCO (Alkest ${ }^{\circledR}$ CSO 400) and sorbitan monooleate ( $\operatorname{Span}^{\circledR} 80$; Sigma-Aldrich, St. Louis, Mo, USA) as surfactants, isopropyl myristate as an oil phase, and water were used for a pseudoternary phase. Nanoemulsions with a translucent aspect and an internal phase size of 23-74 $\mathrm{nm}$ were obtained in proportions of $6 \%-20 \%$ of surfactants or oil. The formulation containing isopropyl myristate $(20.0 \%)$, surfactants $(13.3 \%)$, and water $66.7 \%$ was used for the incorporation of herbal extract. The $R$. ferruginea extract was previously dissolved in propylene glycol (2\%) and added to the oil phase (isopropyl myristate and surfactants) of the nanoemulsion. A concentration of $0.13 \%$ was used because of the greater physical stability of the nanoemulsion and also because of the in vivo anti-inflammatory activity (Figure 5).
The incorporation of extract at $0.5 \%$ and $0.25 \%$ concentration resulted in extract precipitation after nanoemulsion preparation.

The incorporation of the SE decreased the droplet size (57.43 to $47.88 \mathrm{~nm}$ ) and increased the PDI of the nanoemulsion from 0.114 to 0.228 . These changes can represent the molecular interactions between the SE and the nanostructure of the emulsified system, and these interactions decrease the homogeneity of the droplet size with an increase of the PDI. In nanoemulsions, a narrow size distribution was observed in the size distribution and correlation rate (Figure 1). The correlation rate (insert graphics A1 and B1) is the correlation between the time and the displacement of the droplets caused by light scattering. ${ }^{37}$

The SE-loaded nanoemulsion and inert nanoemulsion showed a zeta potential value of $-34.7 \pm 1.15$ 

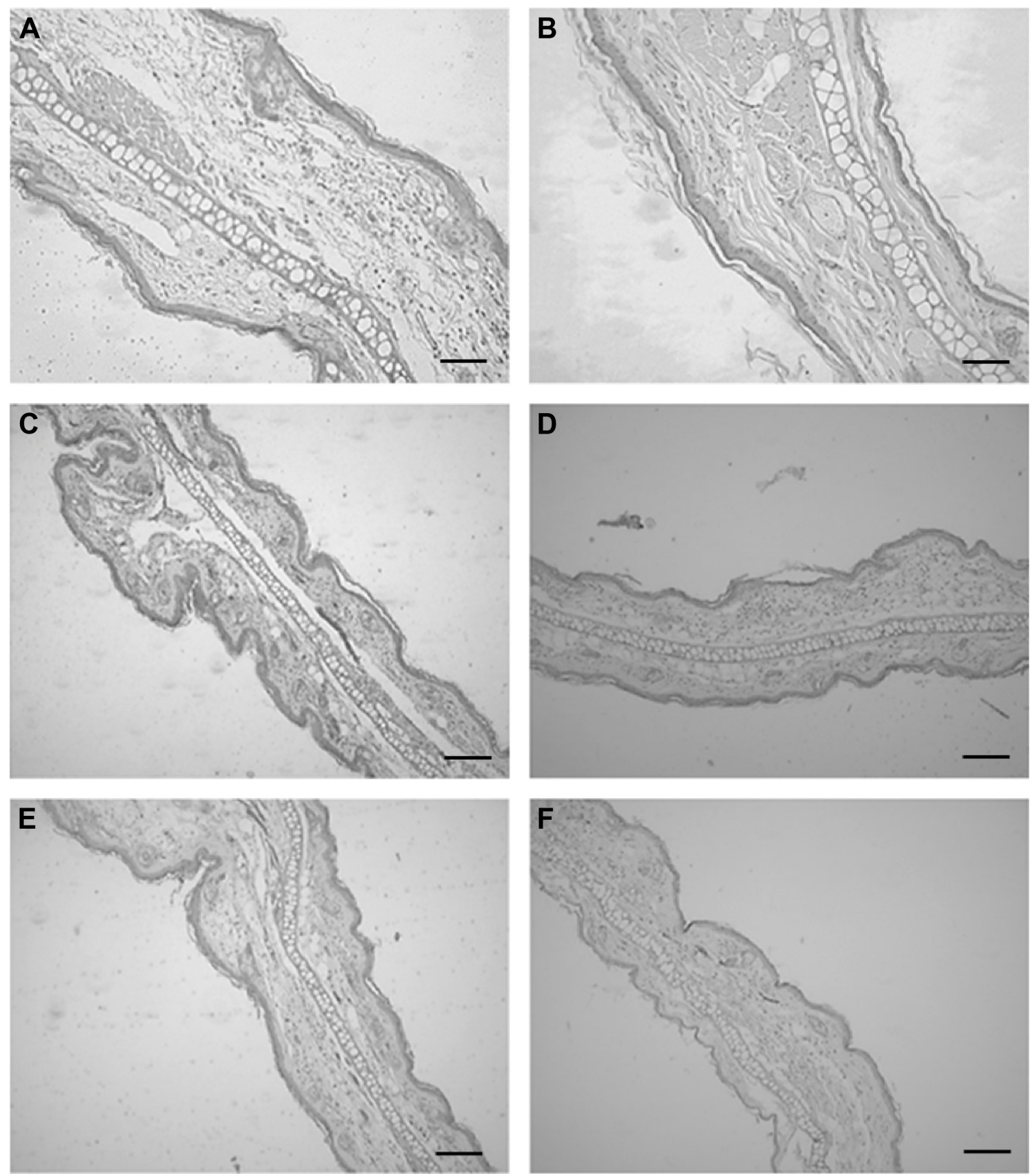

Figure 7 Photomicrographs of histological sections of the mouse ears $(\times 10$, hematoxylin and eosin-stained), evaluated 6 hours after induction of edema.

Notes: Ears treated with (A) croton oil; (B) dexamethasone; (C) cream with extract; (D) nanoemulsion with extract; (E) cream without extract; and (F) nanoemulsion without extract. Scale bars $=100 \mu \mathrm{m}$.

and $-19.95 \pm 0.21 \mathrm{mV}$, respectively (Table 1 ). The differences in the values of the zeta potential can be due to the acidic characteristic of the SE markers. According to Zermiani et al, ${ }^{28}$ the pKa value of MAA and MAB is 4.5 and 4.8 , respectively, and $\mathrm{pH}$ value of nanoemulsions was 5.2, therefore myrsinoic acids are ionized as anionic substances.

The in vitro irritation potential of the nanoemulsions was at a moderate level. Thus, the in vitro irritation found in the nanoemulsions was related to their composition, mainly the surfactants. A previous study by Müller ${ }^{38}$ showed the severe irritation potential of the surfactant $\mathrm{PHCO}$, with the formation of a lysis area of $1.1 \mathrm{~cm}$. This is a usual behavior for polyethoxylated surfactants. ${ }^{39}$

The release profile of SE incorporated in the nanoemulsion was determined by a release profile of the markers MAA and MAB (Figure 4). The influence of nanoemulsion in the release profile was verified by determining a profile of the SE solution and the SE-loaded conventional cream. 
In the release profile of the $R$. ferruginea $\mathrm{SE}$ incorporated or nonincorporated into the nanoemulsion, a delayed release of markers was observed. In addition to the markers MAA and MAB are lipophilic molecules, the presence of other nonpolar substances in the crude extract can reduce the passage of such compounds across the acetato membrane and consequently the partition to the dissolution medium. MAB marker showed a faster release from the conventional formulation than from nanoemulsion, which could be explained by its lower hydrophobicity. ${ }^{28}$ Higher capacity of the nanoemulsion for retaining the markers in the internal phase is probably due to the degree of organization at the nanoemulsion interface, as well as the higher affinity of the markers with the internal phase.

In the release kinetic analysis, the release results showed a good fit to the general release equation with a release exponent $(\mathrm{n})<1.0$. This kinetic model is employed to analyze the release from polymeric pharmaceutical formulations when the release mechanism is not well known or when the release involved more than just a release mechanism. ${ }^{40}$ The release exponent obtained $(\mathrm{n}<1.0)$ expressed the anomalous release mechanism from the formulations, and this behavior can be dependent on the polymeric organization of the surfactants in the emulsion interface.

The release constant $(\mathrm{k})$ - that is, the release flow showed that emulsions released the marker at a slower rate, and the nanoemulsion prolonged the release rates of markers' more than the cream. These results are probably a consequence of the SE incorporation in the oil phase of the nanoemulsion, which allowed better protection of the lipophilic markers MAA and MAB inside the droplets. Nanoemulsion release behavior can be influenced by the polymeric surfactant PHCO. This surfactant forms a thick film on the interface of the nanoemulsion internal phase, providing more stability and a strong barrier for drug transport. ${ }^{41}$

The results of inhibition of croton oil-induced ear edema demonstrated the topical anti-inflammatory activity of the stem barks of the R. ferruginea extract (Figure 5). This activity can be a consequence of the presence of MAA and MAB in the SE, as proven by previous studies which evaluated these isolated compounds using an ear TPA (tetradecanoylphorbol acetate)-induced edema model. ${ }^{25,26}$ The nanoemulsion presented more anti-inflammatory activity than the conventional emulsion containing the same amount of SE $(0.13 \%)$. This result is probably due to better dissolution of the SE in the oil phase. For the conventional emulsion, there was no statistically significant difference in the different concentrations (Figure 5).
This study shows the topical anti-inflammatory activity of SE incorporated into the nanoemulsion and cream: decrease in edema, decrease in the levels of proinflammatory cytokines IL-1 $\beta$, TNF, and $\mathrm{KC}$, as well as decrease in MPO activity. However, the nanoemulsion appeared to be a more efficient carrier for an anti-inflammatory agent than the cream in relation to ear edema inhibition induced by croton oil macroscopically. It also showed a better inhibitory activity against MPO activity and the release decrease of TNF. As TNF is also produced from active MPO ${ }^{42}$ this result demonstrates a close connection. There are also reports that even enzymatically inactive MPO may affect the activation of endothelial cells and the production of proinflammatory cytokines, ${ }^{43}$ which is another proinflammatory effect of MPO. The topical anti-inflammatory activity of $R$. ferruginea stem bark evaluated by the croton oil-induced ear edema model is influenced by the carrier and its probable interaction with the skin physiologic system.

Histologically, analysis of the tissue in the control group treated only with $2.5 \%$ croton oil showed a thickened dermis with a high concentration of cellular infiltration and increased plasma extravasation compared to the naive group (Figure 7A and B). These results are similar to Patrick et al, ${ }^{42}$ who found an increase in the number of blood vessels and moderate to severe swelling with diffuse cellular infiltration 6 hours after the application of croton oil. The histological results confirmed the macroscopic and cytological results obtained from the evaluation of the topical anti-inflammatory activity by the method of croton oil-induced ear edema.

The nanoemulsion incorporating the $R$. ferruginea extract exhibited characteristics as expected of a nanosystem, like droplet size in the nanoscale without aggregates and with uniform distribution of droplets. The addition of Sepigel provided a semisolid aspect to topical use without compromising the physical-chemical characteristics of the nanosystem. The nanoemulsion showed in vitro release control of the markers and better topical anti-inflammatory activity when compared with the cream $(\sim 160 \%)$. It also presented a greater decrease of the release of the TNF, IL- $1 \beta$, and $\mathrm{KC}$ cytokines and MPO activity. The recruitment of new neutrophils increases the production of oxidants in the vascular compartment during inflammation. In addition, MPO can adhere to leukocytes via binding to $\mathrm{CD} 11 \mathrm{~B} / \mathrm{CD} 18$, which may contribute to the proinflammatory effect of MPO through the accumulation of leukocytes at the inflammation site. ${ }^{44}$ These results demonstrate that the incorporation of the $R$. ferruginea extract into a nanoemulsified system promotes better topical antiinflammatory efficacy compared to conventional cream. 


\section{Acknowledgments}

The authors wish to thank FAPESC (Fundação de Amparo à Pesquisa e Inovação no Estado de Santa Catarina - Edital PRONEM (06/2012) FAPESC/CNPq, grant number 2708/2012) and CNPq (Conselho Nacional de Ciência e Tecnologia) for their financial support; CAPES (Coordenação de Aperfeiçoamento de Pessoal de Nível Superior) by master student grants in Pharmaceutical Science sponsored J Dal Mas.

\section{Disclosure}

The authors declare that the current article is based on the Master thesis submitted to the Universidade do Vale do Itajai by Juarana Dal Mas under advisor of Dr Tania Mari Bellé Bresolin and Dr Ruth Meri Lucinda-Silva.

\section{References}

1. Abdel-Mottaleb MM, Moulari B, Beduneau A, Pellequer Y, Lamprecht A. Nanoparticles enhance therapeutic outcome in inflamed skin therapy. Eur J Pharm Biopharm. 2012;82(1):151-157.

2. Bickers DR, Athar M. Oxidative stress in the pathogenesis of skin disease. J Invest Dermatol. 2006;126(12):2565-2575.

3. Lee DY, Choo BK, Yoon T, et al. Anti-inflammatory effects of Asparagus cochinchinensis extract in acute and chronic cutaneous inflammation. J Ethnopharmacol. 2009;121(1):28-34.

4. Barker JN, Mitra RS, Griffiths CE, Dixit VM, Nickoloff BJ. Keratinocytes as initiators of inflammation. Lancet. 1991;337(8735):211-214.

5. Gröne A. Keratinocytes and cytokines. Vet Immunol Immunop. 2002; 88(1-2):1-12.

6. Kimber I, Pichowski JS, Basketter DA, Dearman RJ. Immune responses to contact allergens: novel approaches to hazard evaluation. Toxicol Lett. 1999;106(2-3):237-246.

7. Corsini E, Galli CL. Epidermal cytokines in experimental contact dermatitis. Toxicology. 2000;142(3):203-211.

8. Bedi MK, Shenefelt P. Herbal therapy in dermatology. Arch Dermatol. 2002;138(2):232-242.

9. Esarwani KK, Gupta R. Bioavailability enhancers of herbal origin: an overview. Asian Pac J Trop Biomed. 2013;3(4):253-266.

10. Hafner A, Lovrić J, Lakoš GP, Pepić I. Nanotherapeutics in the EU: an overview on current state and future directions. Int J Nanomedicine. 2014;9:1005-1023.

11. Eid MA, El-Enshasy HA, Aziz R, Elmarzugi NA. The preparation and evaluation of self-nanoemulsifying systems containing Swietenia oil and an examination of its anti-inflammatory effects. Int $J$ Nanomedicine. 2014;9:4685-4695.

12. Hassan AO, Elshafeey AH. Nanosized particulate systems for dermal and transdermal delivery. J Biomed Nanotechnol. 2010;6(6):621-633.

13. Ngan CL, Basri M, Lye FF, et al. Comparison of process parameter optimization using different designs in nanoemulsion-based formulation for transdermal delivery of fullerene. Int J Nanomedicine. 2014;9: 4375-4386.

14. Mason TG, Wilking JN, Meleson K, Chang CB, Graves SM. Nanoemulsions: formation, structure, and physical properties. J Phys Condens Mat. 2006;18(41):R635-R666.

15. Solans C, Izquierdo P, Nolla J, Azemar N, Garcia-Celma MJ. Nanoemulsions. Curr Opin Colloid Interface Sci. 2005;10(3-4):102-110.

16. Tadros T, Izquierdo P, Esquena J, Solans S. Formation and stability of nano-emulsions. Adv Colloid Interface Sci. 2004;108:303-318.

17. Thakur N, Garg G, Sharma PK, Kumar N. Nanoemulsions: A review on various pharmaceutical application. Global J Pharmacol. 2012;6(3): $222-225$.
18. Atrux-Tallau N, Lasselin J, Han S, Delmas T, Bibette J. Quantitative analysis of ligand effects on bioefficacy of nanoemulsion encapsulating depigmenting active. Colloid Surface B. 2014;122:390-395.

19. Bernardi DS, Pereira TA, Maciel NR, et al. Formation and stability of oil-in-water nanoemulsions containing rice bran oil: in vitro and in vivo assessments. J Nanobiotechnology. 2011;9:1-9.

20. Bidone J, Zorzi GK, Carvalho EL, et al. Incorporation of Achyrocline satureioides (Lam.) DC extracts into topical nanoemulsions obtained by means of spontaneous emulsification procedure. Ind Crop Prod. 2014; 62:421-429.

21. Quintão FJ, Tavares RS, Vieira-Filho SA, Souza SH, Santos OD. Hydroalcoholic extracts of vellozia squamata: study of its nanoemulsions for pharmaceutical or cosmetic applications. Braz J Pharmacogn. 2013;23(1):101-107.

22. Cechinel Filho V, Meyre-Silva C, Niero R, et al. Evaluation of antileishmanial activity of selected Brazilian plants and identification of the active principles. Evid Based Complement Alternat Med. 2013; 2013:265025.

23. Antonialli CS, Silva GF, Rocha LW, et al. Antihyperalgesic effects of myrsinoic acid $b$ in pain-like behavior induced by inflammatory and neuropathic pain models in mice. Anesth Analg. 2012;115(2):461-469.

24. Hess S, Padoani S, Scorteganha LC, et al. Assessment of mechanisms involved in antinociception caused by myrsinoic acid B. Biol Pharm Bull. 2010;33(2):209-215.

25. Hirota M, Miyasaki S, Minakuchi T, Takagi T, Shibata H. Myrsinoic acids B, C and F, anti-inflammatory compounds from Myrsine seguinni. Biosci Biotechnol Biochem. 2002;66(3):655-659.

26. Mizushina Y, Miyazaki S, Ohta K, Hirota M, Sakaguchi K. Novel anti-inflammatory compounds from Myrsine seguinii, terpeno-benzoic acids, are inhibitors of mammalian DNA polymerases. Biochim Biophys Acta. 2000;1475(1):1-4.

27. Baccarin T, Muceneeki RS, Bresolin TM, Yunes RA, Malheiros A, Lucinda-Silva RM. Development and validation of an HPLC-PDA method for the determination of myrsinoic acid $b$ in the extracts of Rapanea ferruginea Mez. Talanta. 2011;85(2):1221-1224.

28. Zermiani T, Malheiros A, Silva RML, Stulzer HK, Bresolin TMB. Structural and physicochemical characterization and purity assessment of myrsinoic acids A and B, active compounds isolated from Rapanea ferruginea barks. Arab J Chem. 2015: http://dx.doi.org/10.1016/j. arabjc.2015.06.032.

29. Baccarin T, Ferreira RA, Gazoni VF, Yunes RA, Malheiros A, LucindaSilva RM. Influence of extraction parameters on hydroalcohol extracts of the stem bark of Rapanea ferruginea Mez using myrsinoic acid b as marker. Trop J Pharm Res. 2014;13(7):1113-1119.

30. Baccarin T, Debrassi A, Souza MM, Yunes RA, Malheiros A, LucindaSilva RM. Influence of process conditions on physicochemical properties and antinociceptive activity in vivo of spray-dried Rapanea ferruginea Mez. stem bark extract. Powder Technol. 2016;291:66-74.

31. Zermiani T, Dal Mas J, Xavier BB, et al. Stability indicating HPLC method for determination of myrsinoic acids A and B in Rapanea ferruginea extracts and nanoemulsions. IJPSR. 2015;6(11):4639-4649.

32. United States Pharmacopeia, U.S., Biological Tests, In Vitro; 2007.

33. O'Brien KA, Jones PA, Rockley J. Evaluation of an agarose overlay assay to determine the eye irritation potential of detergent-based products. Toxicol In Vitro. 1990;4(4-5):311-313.

34. Carlson RP, O'Neil-Davis L, Chang J, Lewis AJ. Modulation of mouse ear edema by cyclooxygenase and lipoxygenase inhibitors and other pharmacologic agents. Agents Actions. 1985;17(2):197-204.

35. Otuki MF, Vieira-Lima F, Malheiros A, Yunes RA, Calixto JB. Topical antiinflammatory effects of the ether extract from Protium kleinii and a-amyrin pentacyclic triterpene. Eur J Pharmacol. 2005; 507(1-3):253-259.

36. Bradley PP, Priebat DA, Christensen RD, Rothstein G. Measurement of cutaneous inflammation: estimation of neutrophil content with an enzyme marker. J Invest Dermatol. 1982;78(3):206-209.

37. Schätzel K. Correlation techniques in dynamic light scattering. Appl Physics B. 1987;42(4):193-213. 
38. Müller AFF. Development of nanoemulsified systems containing extract of Allamanda cathartica L. Flowers for cosmetic applications. Itajaí, Brazil, 2013.

39. Effendy I, Maibach HI. Detergent and skin irritation. Clin Dermatol. 1996;14(1):15-21.

40. Costa PJ. Avaliação in vitro da lioequivalência de formulações farmacêuticas. Braz J Pharm Sci. 2002;38(2):141-153.

41. Nam YS, Kim J, Park J, Shim J, Lee JS, Han SH. Tocopheryl acetate nanoemulsions stabilized with lipid-polymer hybrid emulsifiers for effective skin delivery. Colloids Surf B Biointerfaces. 2012; 94:51-57.
42. Patrick E, Burkhalter A, Maibach HI. Recent investigations of mechanisms of chemically induced skin irritation in laboratory mice. J Invest Dermatol. 1987;88(3 Suppl):24s-31s.

43. Lefkowitz DL, Roberts E, Grattendick K, et al. The endothelium and cytokine secretion: the role of peroxidases as immunoregulators. Cell Immunol. 2000;202(1):23-30.

44. Odobasic D, Kitching AR, Holdsworth SR. Neutrophil-mediated regulation of innate and adaptive immunity: the role of myeloperoxidase. J Immunol Res. 2016;2016:2349817.
International Journal of Nanomedicine

\section{Publish your work in this journal}

The International Journal of Nanomedicine is an international, peerreviewed journal focusing on the application of nanotechnology in diagnostics, therapeutics, and drug delivery systems throughout the biomedical field. This journal is indexed on PubMed Central, MedLine, CAS, SciSearch ${ }^{\circledR}$, Current Contents ${ } /$ Clinical Medicine,

\section{Dovepress}

Journal Citation Reports/Science Edition, EMBase, Scopus and the Elsevier Bibliographic databases. The manuscript management system is completely online and includes a very quick and fair peer-review system, which is all easy to use. Visit http://www.dovepress.com/ testimonials.php to read real quotes from published authors.

Submit your manuscript here: http://www.dovepress.com/international-journal-of-nanomedicine-journal 